Usually some of the visitors attending the lectures and conversazione become sufficiently interested to join the society and become useful members; the University also profits in turn, as the conversazione enables many persons to see it and learn what it is doing who otherwise would not have an opportunity.

The society does not restrict itself to work which is done by its own members, but, where possible, it is always willing to assist others; e.g. it greatly assisted in the formation of the Australasian Association for the Advancement of Science; it also took an active part in the foundation of a marine biological laboratory near the entrance to Sydney Harbour, which, unfortunately, was required a few years afterwards by the Government for defence purposes, and it is to be hoped that the trustees, who received compensation from the Government, will see their way before long to start a new marine station and laboratory; it has on several occasions brought matters of importance under the notice of the Government where legislation has been necessary for the good of the public health, the preservation of the native fiora and fauna, also for the assistance of scientific exploring expeditions in the Antarctic and elsewhere and in other similar matters, and it has helped in the extension of the British Science Guild in Australia.

For many years it has been one of the main objects of the society to get together a good library of the principal British, American, French, German, and other scientific journals, and it now has complete series of many of these, some by purchase, others by gift and in exchange for its own publications, so that, taking the limited resources of the society into account, quite a creditable and useful library has been gradually built up. Without such books of reference the research student is at a great disadvantage, and the society regards the formation of such a reference library as of equal importance to the publication of papers read before it.

In 1878 the society obtained possession of its present freehold premises in Elizabeth Street, Sydney. Since then it has twice added to them, in 1896 and again in 1905 ; the last time it was to increase the accommodation required for the growing library, and also to provide accommodation for kindred societies by sub-letting some of the rooms, not immediately required, to them at low rentals; in this way it affords (as was stated in an article on the Australasian Association for the Advancement of Science, NATURE, December 30, 1909) some of the advantages enjoyed by the English societies in Burlington House.

The Parliament of New South Wales has generously helped the society for some years; for several years the Government printed the society's annual volume of papers and proceedings; of late years, in place of printing the volume, it has contributed ros. per annum for each 20 s. of the members' subscriptions; but, in spite of this, the society's income is insufficient to enable it to undertake many things it would like to do for the advancement of science, and it finds difficulty in carrying on its present efforts.

A. Liversidgr.

\section{THE AMERICAN PHILOSOPHICAL SOCIETY.}

THE general meeting of the American Philosophical Society was held at Philadelphia on April 21-23, and we have been favoured by the secretaries with a report of the proceedings. The afternoon of April 23 was devoted to a symposium on experimental evolution, the principal papers being given by Prof. H. S. Jennings, on inheritance in non-sexual and self-fertilised organisms; Mr. G. H. Shull, on germinal analysis through hybridisation; and Dr. C. B. Davenport, on new views about reversion.

At the session on April 22 the following were elected to membership:-Residents of the United States: Dr. S. E. Baldwin, Dr. F. G. Benedict, Dr. C. F. Brush; Dr. D. H. Campbell, Dr. W. E. Castle, Dr. G. B. Gordon, Dr. D. J. Hill, Dr. H. C. Jones, Dr. L. Loeb, Mr. J. McCrea, Dr. R. C. Maclaurin, F.R.S., Dr. B. O. Pierce, Dr. H. F. Reid, Dr. J. F. Rhodes, and Dr. O. W. Richardson. Foreign residents: Dr. A. von Baeyer, Madame S. Curie, Sir David Gill, K.C.B., F.R.S., Dr. E. if $x_{y}$ y, and M. C. E. Picard. O. 2 I 2 I, VOL. ?? ?
In addition to the symposium on evolution, fifty-one papers were presented. Brief summaries of the contents of a few of these papers are subjoined.

Physical notes on Meteor Crater, Arizona, Prof. IV. F. Magie. Meteor Crater is a vast crater situated in Coconino County, Arizona, formed by the impact of an iron meteorite or group of meteorites. Scattered specimens of these meteorites (the Canyon Diablo siderites and the "shale ball" siderites) are found around the crater, but the main mass has not yet been found. It probably is buried 1000 feet below the surface. (I) The Canyon Diablo iron shows a magnetic permeability not very different from that of cast iron. The shale ball iron seems to be generally similar to it in its magnetic properties. Several observations indicate an intrinsic magnetisation, peculiarly arranged, in the shale ball iron. The magnetic field of the crater shows no local peculiarities such as would be expected from the presence of a large continuous mass of iron. The inference is that the mass is fragmentary, perhaps intrinsically magnetised, and also, perhaps, largely oxydised. (2) The distribution of the ejected material and the inclinations of the exposed strata around the crater wall show a remarkable symmetry with respect to a nearly north and south axis. This symmetry, even in details, appears in holes made by bullets in a suitable mass of compacted powder. The inference is that the crater was formed by a projectile. (3) The mass ejected is estimated at 330 million tons. The energy used to lift it out of the hole is a negligible fraction of the energy expended. Most of the energy expended was used in crushing the rock. An estimate based on the assumption that the powdered sandstone was heated to $2500^{\circ} \mathrm{C}$. would indicate an expenditure of $92.5 \times 10^{12} \mathrm{ft}$. tons of energy. Talsing everything into account, it seems reasonable to estimate in all an expenditure of $60 \times 10^{12} \mathrm{ft}$. tons of energy. Taking this for the energy expended, and estimating the prabable velocity of the meteor as lying between three and forty-eight miles a second, the mass of the meteoric group would lie between fifteen million and sixty thousand tons. The size and shape of the crater lead one to estimate a mass larger than this lowest limit, and the final estimate is that the mass is 400 thousand tons, and that its velocity was from eighteen to twenty miles a second.

The conversion of the energy of carbon into electrical energy by solution in iron, Prof. Paul R. Heyl. It is found that carbon dissolves in molten iron with a liberation of energy, which, by providing a suitable negative element, may be obtained as an electric current. The electromotive force thus developed has not yet been definitely determined, but is probably not more than oneor two-hundredths of a volt. There is no possibility of compounding this electromotive force with the accompanying thermal effect, as the two are opposite in direction.

The one-fluid theory of electricity, Prof. F. E. Nipher. The author has shown in a former paper that what have been taken for discharges from the positive terminal of an electrical machine are really optical illusions. The positive discharge is really an inflow of the electrical discharge which flows outward from the negative terminal. This is in harmony with the one-fluid theory of Franklin. With this paper he presents photographic plates showing the discharge from its first stages until the disruptive spark appears. These plates fully confirm the former conclusion that there is no positive electrical discharge. The discharge comes from the negative terminal and goes to the positive. The illusion which has led to the idea of a positive discharge is compared to one which might prevail if Niagara Falls should suddenly recede from Lake Ontario to Lake Erie. It might deceive us into the idea that there had been a positive discharge into Lake Erie.

The past and present status of the rther, Prof. A. G. Webster. The history of the conception of the luminiferous æther was covered from the time of Newton and Huygens to the present. For the last hundred years the belief in the æether as necessary to transmit light has been universal. Lord Kelvin devoted most of his life to establishing its properties. The various mechanical theories were succeeded by Maxwell's successful electromagnetic theory, confirmed twenty years later by the electric wave experiinents of Hertz. "To explain astronomical aberration and the phenomena due to the earth's motion, Maxivell's theory $\because a j$ je:srely strained, and was perfected by Lorentz. The 
classic experiment of Michelson on the apparent fixity of the æther of the earth in its motion was explained by Lorentz, though by the violent assumption that motion changes the dimensions of bodies, and that the local time of a moving observer is different from that of an observer at rest. From this comes Einstein's principle of relativity, which profoundly modifies our ideas of space and time, and leads many radicals to abandon the æther.

The æther drift, Prof. Augustus Trowbridge. Prof. Trowbridge spoke very briefly upon the general question of relative motion of matter and the rther-nest to point out that, in spite of the experimental work of various investigators, we are still in doubt as to whether the earth in its motion through æther-filled space entrains the æther in its motion or not. Next, he explained in what respect the experimental method adopted by Prof. Mendenhall and himself differed from that of former investigators so as to be free from the objections which have rendered the previous work inconclusive.

The effects of temperature on fluorescence and phosphorescence, Prof. E. L. Nichols. A summary of observation on the fluorescence and phosphorescence from temperature of liquid air to ordinary temperatures, showing that the theory of Lenard is inadequate to correlate all the facts.

Infra-red and ultra-violet landscapes, Prof. R. W. Wood. Photographs taken with infra-red and ultra-violet, using appropriate absorption screens, show greatly altered contrasts. Thus some substances which are white when viewed by ordinary light appear black when photographed with ultra-violet light. By such photographs it may be possible to obtain additional details concerning the surface markings of the moon and planets.

The cause of epidemic infantile paralysis, Dr. S. Flexner. A report on the experimental study of piliomyelitis in monkeys, which has yielded a large number of important facts relating to the spontaneous disease in man. The nature of the virus has been discovered, many of its properties have been ascertained, some of its immunity effects have been established, the clinical and pathological peculiarities of the disease have been elucidated, and a basis has been secured on which to develop measures of prevention.

Dermal bones of Paramylodon from the asphaltum deposits of Rancho La Brea, near Los Angeles, California, W. J. Sinclair. This paper describes the mode of occurrence, shape, and microscopic structure of the skin bones of an edentate animal from the Los Angeles asphaltum beds. These bones, which are small, pebble-like elements in the skin, resemble closely similar bones occurring in a piece of skin found in a cave at Last Hope Inlet, Patagonia. They are also known to occur in Mylodon, a genus of ground sloths formerly living in North and South America. As the structure of the skin bones in Mylodon is quite different from what it is in Grypotherium, the form from the Last Hope Inlet locality, it was a matter of interest to find out to which of these genera the specimens from the asphalt showed the closer resemblance. Thin sections of the bones were cut, and these prove that Paramylodon from the asphaltum beds is almost identical, in the structure of the skin bones, with Grypotherium, a contemporary of early man in Patagonia.

A note on Antarctic geology, Prof. W. M. Davis. It is well known that fossil plants have been found in various formations in the Arctic and Antarctic regions, indicating the former prevalence there of a much milder climate than that of to-day. Our prepossession naturally favours the present polar climate as having been the ordinary or normal polar climate of all geological time; but inasmuch as milder climates have sometimes occurred, it is eminently possible that they, and not the present rigorous climate, mav have been the usual polar climate through the geological ages. Hence a peculiar interest attaches to studies of the minute structures of stratified formations, particularly of such as are of continental origin, for from such studies it may well be possible to determine climatic conditions even in the absence of fossils.

Some recent results in connection with the absorption spectra of solutions, Prof. H. C. Jones. The absorption spectra of dissolved substances are not simply a function of the nature of the substances, but also of the nature of the solvents. When a salt like uranyl chloride is dissolved in wator we have one spectrum in water. another in alcohol, still another in acetone, and a spectrum in glycerol which is very different from any of the above. The only way in which we can account for these results is in terms of the solvate theory. The different solvents combine with the dissolved substance and form solvates having very different compositions. These affect the resonance of the vibrators that are the cause of light absorption differently, and, consequently, the absorption in the different solvents is different. The second point upon which stress is laid has to do with the action of one acid on the salt of another acid. In terms of prevailing chemical theories, when a salt of one acid is treated with a small amount of another acid, a part of the salt is transformed into the salt of the second acid. With the addition of more and more of the free acid, more and more of the initial salt would pass over into the salt of the second acid. In such solutions we should expect to have the bands of both salts occurring simultaneously, with varying intensity, depending upon the amounts of the two salts present. The fact is that when a salt is treated with a free acid we have neither the bands corresponding to the initial nor the final salt present, but bands occupying positions intermediate between those of the two salts, and these bands can be made to occupy any intermediate position by suitably varying the amount of the free acid relative to the salt. This shows that between the initial salt and the one finally formed there is a series of intermediate compounds or systems corresponding to the various positions of the bands. The number of reactions showing the above relations is not small, and this raises the question whether chemical reactions in general are not much more complex than is usually represented by our chemical equations, which deal only with the initial and final stages.

Suppression and extension of spore-formation in $P_{i p e}$ befel, Prof. D. S. Johnson. The interesting feature of the structure of the flower in this plant is the presence of male flowers, female flowers, and flowers bearing the organs of both sexes, on three separate kinds of spikes; but flowers of each sex often bear some rudiments of organs of the other sex. This shows that while some flowers are apparently of one sex only, they really possess, in some degree. the power to develop the organs of the opposite sex. In other words, the cells from which the flowers arise are capable of forming the organs of both sexes, and the fact that one sex only is formed is probably due to some infuence, internal or external, affecting the cells at the time that the flowers are being initiated. Experimental work on certain plants has shown that a change in the light or soil supplied to apparently unisexual individuals may cause the organs of the other sex also to appear. This seems clear evidence that both sexes may really be present in all apparently unisexual plants, but that sometimes one, sometimes the other, of these is suppressed or fails to become evident. The only plants of which this seemingly cannot be true are those well-known unisexual plants like the sago palm, cottonwoods and willows, in which each individual bears only male flowers or only female flowers year after year throughout the life of the plant. Another case is that of one of the mosses, in which it has been shown by Noll that the sex remains constant for thirty generations when male or female plants are propagated by budding.

Solar activity and terrestrial magnetic disturbances, Dr. L. A. Bauer. A recent examination of the times of beginning of magnetic disturbances, as recorded at observatories over the entire globe, showed that, without doubt, magnetic storms do not begin at absolutely the same instant of time, as heretofore believed. Instead, they progress around the earth, the times generally increasing as we go around the earth eastwardly; for the quick and abrupt disturbances, which are usually comparatively minute in their effect on the compass needle, the complete passage around the earth required from three to four minutes. For the bigger effects, or for the greater magnetic storms, the rate of progression is slower, so that it would take them half an hour or more to get around the earth completely. There is thus introduced a new point of view in the investigation of the origin of magnetic storms. In addition to negatively charged electrified particles coming from the sun, to which recent theories sought to attribute our magnetic storms, but which the author found would produce effects not in harmony with 
those actually observed, we also receive radiations, such as the Rontgen rays, for example, which are not deflected by the earth's magnetic field, as they do not carry electric charges. Their chief effect will be to ionise the gases of which the atmosphere is composed, i.e. make the air a better conductor of electricity. U1tra-violet light has the same effect. It is known that a small part of the magnetic forces acting on a compass needle is due, not to the magnetism or electric currents below the earth's surface, but to electric currents already existing in the atmosphere, and which the speaker showed were brought about by the atmosphere cutting across the earth's lines of magnetic force in its general circulation around the globe. If the regions of these upper electric currents are at any time made by some cause more conducting, electricity will be immediately set in motion, which in turn affects our compass needles. This new theory, called "the ionic theory of magnetic disturbances," satisfactorily explains the principal features of magnetic storms. As the currents get lower down in the atmosphere their velocity is checked, so that, instead of taking but three to four minutes to circulate around the earth, as do the higher currents, it may take them half an hour and more however, their actual effect on the magnetic needle would be greater, because of their coming nearer to the earth. The theory also opens up the possibility of accounting for some of the other changes and variations experienced by the earth's magnetism, and likewise has a bearing on the peculiar formation of the magnetic fields in sun-spots discovered by Prof. Hale.

Magnetic results of the first cruise of the Carnegie, Dr. L. A. Bauer. The non-magnetic vessel Carnegie completed on February 17 the first cruise, covering in all, since September 1, 1909, 8000 miles. Special tests made at Gardiner's Bay, Long Island, and at Falmouth, England, proved conclusively that there are no corrections to the magnetic instruments of the kind encountered on vessels in which more or less iron occurs in the construction. Thus in a single voyage errors could be disclosed in the compass charts used by mariners on their Transatlantic voyages between New York and England of importance, not alone from a purely scientific standpoint, but from that of practical and safe navigation as well. The errors found by the Carnegie in the declination at various points along the track followed by the vessel amounted, on the average, to about I degree-an error which persisted in the same direction for long distances. After leaving Falmouth the Carnegie headed for Funchal, Madeira. From thence she sailed to Bermuda, and finally arrived at Brooklyn on February 17 . In spite of the unusually adverse conditions frequently met with during this first cruise, more or less extensive magnetic observations were secured almost daily. The errors of the compass charts were found, in general, even more pronounced for the southerly half of the cruise, viz. Madeira to Bermuda, than for the northerly half, and were again shown to be systematic in their nature. Some of the charts were in error 2 to 3 degrees. For the entire cruise important corrections were also disclosed for the magnetic charts which give the lines of equal magnetic dip and of equal magnetic force. The Carnegie is now being fitted out for a circumnavigation cruise of about three years. In the reantime, the masnetic surveys of unexplored countries are pushed on, so that it is confidently expected that by the year 1915 the seneral magnetic survey of the greater part of the globe will have been completed in sufficient detail to permit the construction and issuing of a new set of masnetic charts.

On the distances of red stars, Prof. H. N. Russell. Comparison of the parallaxes of stars, derived by the author from photographs taken at the Cambridge Observatory (England) by Mr. A. R. Hinks and himself, and their spectra, determined at Harvard under the direction Prof. Pickering, shows a marked correlation between spectral type and parallax. The proportion of orange and red stars (types $\mathrm{K}$ and $\mathrm{M}$ ) among those of large proper motion, and especially among those shown by direct measurement to be our near neighbours, is very much sreater than among the general run of stars of the same apparent brightness. Conversely, stars of the same apparent brightness and proper motion are, on the average, nearer to us the redder they are. It follows that these stars are intrinsically fainter the redder they are, the reddest ones being, on the average, only one-fiftieth as bright as the sun. On the other hand, many bright red stars (such as Arcturus) are at great distances, and are actually at least 100 t:mes as bright as the sun. All this can be explained on the hypothesis (now well established on other grounds) that the reddest stars are the lowest in temperature. With the latest determinations of temperature and surface brightness, it appears that the fainter red stars are somewhat smaller, and presumably denser, than the sun, while the brighter ones are very much larger than the sun, and presumably of very small density. The latter class probably represent an early stage of evolution, and the former the latest stage that can be observed.

A standard system of photographic stellar magnitudes, Prof. E. C. Pickering. Since 1879 about two million photometric observations of one hundred thousand stars have been made at the Harvard College Observatory, The results, published in vols. 1., liv., and $1 \mathrm{xx}$. of the "Harvard Annals," furnish a standard scale for detcomining the brightness of the stars in all parts of the sky, according to a uniform system. The general introduction of photography in nearly all departments of astronomy has created an urgent need for a similar scale to give the photographic magnitudes of the stars. The two scales will differ, since red or yellow stars will always give fainter images. The scale proposed will be the same for white stars as the visual scale. Three methods are adopted in this work for determining the photographic brightness-first, correcting the visual magnitude by the class of spectrum; secondly, by measuring with great care the photographic brightness of a sequence of stars near the North Pole, and superposing this photographically on the stars to be measured; thirdly, by attaching to the object-glass of the telescope a small prism, a second image of each star, five magnitudes fainter than the principal image, is formed. All three of these methods are in use on a large scale at the Harvard Observatory, and it is hoped that, as the result of many thousand measures, a satisfactory solution of the problem will be found.

Some interesting double stars, Prof. Eric Doolittle. The many thousand double stars in the sky may be divided into two classes. There are some in which the two stars are not really near each other, but merely happen to lie in the same direction as viewed from the earth, and there are others which form true systems composed of two suns revolving about their common centre of gravity. In the latter case, measures show that one sun revolves about the other in an elliptic orbit. It often happens that a very few measures of such a system secured at certain critical times throw unusual light on the nature of the motion and the size of the orbit. This is especially the case when the companion star apparently ceases its motion in one direction and begins to move backward, and also when the companion is passing nearest the principal star. Several diagrams were shown describing measures of this kind which had recently been secured. An account was also given of the discovery of a very close double star during its occultation by the moon.

\section{THE ROYAL OBSERVATORY, GREENWICH.}

READ at the annual visitation of the Board of Visitors $R$ on Saturday last, the Astronomer Royal's report of the work done at the Greenwich Observatory during the year ended May Io contains many items of general interest.

On the transit circle the new central illumination was further compared with the annular illumination of the field, and it was found that, with the latter, transits were observed 0.24 s. earlier than they are with the new form. Six stars from Newcomb's Fundamental Catalogue are observed each nicht in order to connect the observations of the reference stars for the Oxford Astrographic Zones with any system that may ultimately be adopted by the Permanent International Committee.

Observations of the diurnal changes of level and nadir during 1909 showed that changes of level were less, and of nadir slightly greater, than the means for $1897-1905$ The lunar observations with transit circle and altazimuth are in good agreement, and, for Igo8, show the mean error of the tabular place to be $-0.395 \mathrm{~s}$. in R.A. and 